\title{
JUS NOVUM
}

\author{
Humberto Grande \\ Docente livre de Introdução á Ciência do Direito \\ da Faculdade de Direito da Universidade do \\ Paraná. \\ DENOMINAÇÃO
}

A justa conceituação do direito do trabalho é um problema que vivamente preocupa os juristas modernos, porque a sua esfera peculiar costuma ser confundida com a de outros ramos do direito, determinando assim sérios prejuízos ao novo direito, cujo estudo fica sèriamente perturbado, carecendo de ordem e sistematização. Como afirma Castán: "O Direito do Trabalho constitui hoje já uma disciplina autônoma muito diferente pelo seu espírito e pelos seus métodos de todos os demais ramos jurídicos". Cumpre, pois, precisar o seu objeto com o maior rigor possível, para evitar idéias errôneas sôbre esta matéria.

A primeira dificuldade está em encontrar uma denominação conveniente e satisfatória, que exprima bem a essência clêsse novo direito. Chamam-no ilustres autores e grandes tratadistas do direito social, como Barassi, Pergolese, Sanseverino, Bortolotto, Ballela, Bottai, Casanova, De Litala, Passarelli, Pic, Capitant-Cuche, Scelle, Tissembaum, De Vealo, Palacios, Gronda, Oliveira Viana, Cesarino Junior, Joaquim Pimenta, Linares e muitos outros, cada um de acôrdo com a sua preferência, de direito do trabalho, direito industrial, direito obreiro, direito operário, direito laboral, direito econômico, direito sindical ou direito corporativo, sendo usadas ainda outras adjetivações que 
aspiram, com maior propriedade, definir a natureza desta ramificação jurídica. Sôbre todos êsses nomes propostos, não temos dúvida alguma. Preferimos para designá-lo a terminologia-trabalho, direito do trabalho, que nos é singularmente simpática, dada a riqueza do seu conteúdo, como procuraremos demonstrar com argumentos decisivos, e mesmo porque essa terminologia já foi consagrada mundialmente. Assim os países mais adiantados dizem: "Labor Law", "Arbeit srecht", "Diritto del Lavoro", "Droit du Travail" e "Derecho del Trabajo". $O$ trabalho é uma realidade imensa que impregna tôda a sociedade. $O$ seu conceito é amplíssimo e abrange tôda a esfera do social, enquanto, ao nosso modo de ver, o sindicato e a corporação constituem meras instituições trabalhistas. Depois, o trabalho não tem partido nem regime político. Êle é um fator permanente na história da humanidade.

Não aprovamos também o título de direito social para denominar o direito especificado, porque, atualmente, com a evolução dos tempos, todo direito é social, uma vez que já ultrapassamos a fase liberal e individualista do desenvolvimento da sociedade. Assim aquêle nome se prestaria a muita confusão, pois, o seu sentido compreende a totalidade do direito moderno. Ora, como bem sustenttou Gaston May: "As instituições jurídicas devem ser distinguidas umas das outras com cuidado. Eis porque é preciso designá-las por nomes especiais, instituir uma nomenclatura precisa. A terminologia aqui tem a mesma importância, desempenha o mesmo papel que nas outras ciências; evita as confusões, os erros, as perdas de tempo. Foi dito com razão que uma ciência era uma língua bem feita. A ciência do direito não poderia subsistir sem um vocabulário técnico, tem necessidade de utilizar uma nomenclatura firmemente determinada".

O direito do trabalho, porém, dentro daquela concepção, não é só o direito que protege o fraco, os débeis e deficientes. Não. Acima de tudo é o direito que dignifica o trabalhador e faz justiça aos que labutam em prol da coletividade. O Professor Joaquim Pimenta, com muita segurança, colocou a questão nos seus devidos têrmos, ensinando: "A confusão, ou antes, 
equivalência vocabular entre as expressões direito social e direito do trabalho conduz a duas objeções:

$1 .^{\circ}$ - Se direito social e direito do trabalho são têrmos que se confundem, nem todo direito social é direito do trabalho; mesmo no terreno econômico é direito social o que rege a vida interna de uma emprêsa, de uma sociedade anônima, de uma coperativa, mesmo de feitio não proletário ou profissional. Enfim, dentro ou fora dos domínios da economia, é o direito que regula a existência de tôda e qualquer instituição de caráter econômico, religioso, moral, etc., donde a denominação de direito institucional que também se lhe dá e que se vai tornando de uso frequente.

$2 .^{\circ}$ - Se o direito do trabalho reune as "três espécies" de direito social, indicada por GURVITCH: direito puro e independente (a convenção coletiva livremente celebrada à margem do Estado); direito puro, sob a tutela do Estado (convenções coletivas já reguladas por lei) ; direito social elevado à categoria de direito público (leis de assistência às classes trabalhadoras), também em qualquer outro setor da atividade coletiva, de vida em comum - grupo, associação econômica (não proletária), cultural, recreativa, etc., não custa destacar as mesmas arestas ou espécies de direito social apontadas no direito do trabalho: normas inerentes à estrutura do grupo ou associação: estatutos; regimentos internos, etc. (direito social puro e independente) ; relações de direito privado, que não podem deixar de surgir onde quer que se reunam, coexistam ou cooperem dois ou mais indivíduos; medidas de ordem pública, diretamente emanadas do Estado, às quais estão sujeitas tôdas as associações lícitas ou legalmente organizadas, ou que visam diretamente protegê-las, garantí-las, controlá-las conforme o interêsse social que possam encarnar ou envolver.

Assim, em vez de direito social - sinônimo de direito do trabalho, isto é, como expressões que se confundem ou se equivalem, seria preferível, em relação à primeira, a de - direito social do trabalho, e para distinguí-lo de outros direitos sociais, não trabalhistas. 
De qualquer modo, e deixando de lado a de direito laboral, que não pegou, parece-nos que, das denominações acima examinadas, a de DIREITO DO TRABALHO é a mais apropriada, a mais precisa e completa. Compreende, ao mesmo tempo, o direito individual, o direito social e o direito estatal - três aspectos que se combinam, que se entrelaçam, para imprimir-lhe um cunho de unidade integral, com posição definida na ciência jurídica.

O direito do trabalho, dêste modo, se enriquece de significação e amplia a sua esfera de atividade, exercendo maior fôrça na sociedade.

É mistér compreendê-lo dentre dêsses têrmos, para aumentar a sua importância e valor.

$\mathrm{O}$ direito do trabalho é o direito do futuro, porque o trabalho é o fator máximo da grandeza individual e coletiva; êle emancipa a pessoa e liberta as nações. 0 trabalhador prestigiado sente maior soma de estímulos, para progredir e melhorar a. sua vida.

O trabalho é a grande realidade social da época.

Nada é mais atual do que êle. Só com o trabalho podemos construir um mundo novo. Como disse Bergson: "A história e a pré-história apresentam-nos o trabalho como a constante característica do homem e da inteligência. Em suma, a inteligência considerada no que parece ser o impulso inicial, é a faculdade de fabricar objetos artificiais, em especial instrumentos para fazer instrumentos e variar indefinidamente a sua fabricação".

O homem pelo trabalho tudo conquista. Labor omnia vincit.

\section{DEFINIÇÃO}

De acôrdo com o exposto, e atendendo a que a definição, segundo ensina Levy-Ullmann, tem a dupla missão de precisão e evocação, podemos definir o direito do trabalho como 
um ramo do direito, cuja finalidade visa regular as relaçóes de trabalho entre patrões e operários.

Sem querer discutir êsse delicado assunto, pois já os escolásticos afirmavam "omni definitio periculosa est", vejamos algumas das definições apresentadas, dentro do critério objetivo e subjetivo: Pergolesi: "Direito do 'írabalho é aquêle que regula as relações que surgem direta ou indiretamente da prestação contratual e retribuída do trabalho humano". Balella: "O conjunto de normas jurídicas que se referem à classe trabalhadora constitui a legislação do trabalho". Gallard Folch: "Entendemos por Direito do "Irabalho, o conjunto de normas jurídicas dirigidas a regular as relaçôes de trabalho entre patrões e obreiros e, ademals, outros aspectos da vida destes últımos; porém, precisamente, em razäo da sua condição de trabalhadores. "Walker Linares: "Direito do Trabaino é o conJunto de teorias, normas e leis cestinadas a meinorar a conaiçao economico-social dos trabalnadores de tuda indole; isto e, cas classes economicamente debels da sociedade, compostas de obreiros, empregados, trabalinadores intelectuais e independentes". Caldera Kodriguez: "O Direlto do 'Irabaino e o conjunto de normas juridicas que se aplicam ao fato social do trabalho, tanto pelo que toca as relaçoes entre as partes que concorrem a êle e com a coletividade em geral como ao melhoramento dos trabalhadores assim considerados". Durand y Jaussaud: "O Direito do Trabalho é o ramo de Direito cuja matéria está formada pelo conjunto das regras aplicáveis ao trabalho dependente". Cesarino Junior: "Direito do 'Trabalho é o conjunto das leis que consideram individualmente o empregado e o empregador, unidos numa relação contratual". Cabanellas: "O Direito Laboral é aquele que tem por finalidade principal a regulamentação das relações jurídicas entre empresários e trabalhadores e de uns e outros com o Estado, no referente trabalho subordinado, e enquanto corresponde às profissões e à forma de prestação dos serviços, e também no relativo às consequências jurídicas mediatas e imediatas da atividade laboral". 
A maioria dos tratadistas olvida, como acabamos de ver, um ponto essencial. A definição deve ser uma frase breve, que ministra uma idéia clara, precisa e correta do objeto que trata de definir. Mas não é fácil atingir êsse resultado. Como acentua Cabanellas: "Caberia estabelecer que a maioria das definições contempla, como motivo predominante, o conjunto de normas jurídicas relativas ao trabalho; sem deteiminar, $\mathrm{em}$ geral, a classe de trabalho referente a êste Direito. Por outra parte, para fixar a definição do mesmo resulta necessário ter em conta, prèviamente, os fins a que obedece, a sua natureza jurídica, a autonomia dentro das ciências jurídicas e sociais, a categoria do sujeito ou sujeitos a que corresponde e o objeto que lhe pertence. Tudo isso deve ser anterior à definição do Direito; há de preceder ao seu exame e análise, para depois deduzir uma definição, consequente com o conteúdo desta disciplina". E ainda observa: "A quasi totalidade das definições examina mais de uma faceta ou um duplo aspecto do Direito; por exemplo, o protetor e o normativo, o laboral e o contratual".

Para a exata compreensão do direito do trabalho, entretanto, muito mais importante que os problemas da denominação e da definição dêsse novo ramo do direito, é o estudo da sua origem e do seu desenvolvimento nos tempos atuais.

O direito do trabalho é a expressão mais significativa do direito moderno, resultante da nossa época industrial; êle tem por fim organizar a atividade social nos seus múltiplos aspectos com o critério da justiça. O trabalho assim protegido sempre rende muito e é o fator máximo da grandeza de um país, porque aumenta a produção da riqueza nacional pela intensificação da indústria e do comércio. Hoje todos já reconhecem que uma nação não pode engrandecer-se, melhorar a sua vida e equilibrar a sua situação social, sem a santificação do trabalho, reconhecimento do mérito e dignificação dos esforços.

A Justiça do Trabalho, por todos êsses motivos, garantirá a tranquilidade nacional, e o país, dentro das suas normas, jamais será perturbado por lutas sociais e movimentos revolucionários. 0 povo aprecia a paz e o sossêgo e quer calmamente 
entregar-se às suas atividades. Cumpre-lhe, pois, compreender o alcance daquela instituição, por meio da qual o Brasil poderá assegurar verdadeiramente uma fase intensa de ordem e muito progresso.

O direito do trabalho é, na época atual, um processo social adaptativo pelo critério do justo nas relações do trabalho. Apresenta, por isso, como todo direito, um caráter essencialmente institucional e técnico. Êle é uma estrutura de segurançâ e garantia da sociedade. Logo traduz normas em instituições, as quais constituem um aparelhamento técnico, para melhor proteger os círculos sociais. Tal direito não é simplesmente uma ideologia, uma afirmação, um desejo de crescentes progressos jurídicos; é, ao contrário, imperativo da ciência social, uma exigência dos fatos, uma necessidade da época. Na sua sistemática não considera a justiça como coisa abstrata e apriorística, mas sim, como uma realidade viva e palpitante. Não se limita, por isso, a estudos teóricos e dedutivos, mas procede a investigações indutivas e experimentais, para melhor exercer a sua função na vida social.

$\mathrm{O}$ direito do trabalho quer conduzir o gênero humano, pelo império da justiça, à nova era, que iniciará novo ciclo de adaptação para a nossa espécie. Êle evolui no sentido de garantir as condições morais de vitalidade social, para conceder ao indivíduo a totalidade dos direitos humanos existentes ou possíveis, no justo equilíbrio de direitos e obrigações entre o indivíduo e a sociedade.

Nêste terreno, sem lutas nem derramamento de sangue, - Brasil tem feito algo. As suas leis sociais são avançadas. Ao operário todos os direitos e garantias lhe foram concedidos. A legislação do trabalho é abundante em todos os sentidos. Cumpre-nos, agora, organizar o nosso Código do Trabalho, que deve ser a sistemática orgânica de tôdas as leis de regulamentação 气 proteção ao trabalho. Um Código é o esfôrço de hierarquização legal, para ordenar as leis de um ramo determinado do direito. 
O Brasil, dêste modo, vitalizará a sua cultura jurídica, que possui as melhores tradições, porque sempre contou com grandes juristas. Por isso, o nosso país deve acompanhar a evolução do direito.

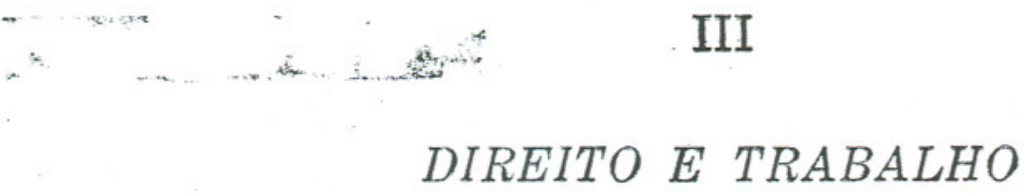

O direito do trabalho é a expressão viva do novo direito, constituido de normas jurídicas que visam a harmonia dos interêsses sociais, trazendo a colaboração das classes e a organização da sociedade pela proteção dispensada a todos os indivíduos que trabalham; é um direito, pois, que dignifica o esforço, estimula a atividade, amparando os fracos e desprotegidos com garantias humanitárias, impregnadas dos sentimentos mais elevados de solidariedade. Por isso alguns autores chamam-no de direito do trabalhador.

O direito do trabalho é um direito que valoriza a capacidade de produção e permite a todos os elementos sociais condições de vida dignas do homem, cercando as pessoas de todos os benefícios resultantes do seu próprio labor, porque só constituem direitos legítimos aqueles que são conquistados pelo trakalho honesto, quer físico ou mental. É assim que tal direito trará, indiscutivelmente, melhores formas de convivência social.

0 direito do trabalho, por todos êsses motivos, reveste-se de veemente realidade. Justificam-no o momento histórico e as atuais exigências da época. Mas para êle seguir diretriz justa e acertada, subtraindo-se dos prejuizos tradicionais do direito, que se deixou cair em convencionalismo artificioso, precisa fundamentar-se na ciência e na filosofia, e não meramente no empirismo e praticas consuetudinarias; aquelas disciplinas mudarão inteiramente o edifício da cultura jurídica, dando-lhe maior solidez e segurança.

0 direito moderno, em verdade, para possuir maior rigor e exatidão, divide a sua atividade entre a ciência e a filosofia 
do direito. Cada uma dessas disciplinas assim terá a sua esfera peculiar de investigação perfeitamente delimitada na sua natureza específica.

A ciência do direito compreende o fundamento sociológico $€$ técnico do direito; a filosofia do direito abrange os seus elementos sistemáticos e ideológicos.

Assim se deve estruturar o verdadeiro direito do trabalho. A sua base sistemática e ideológica encontra-se na filosofia jurídica. A técnica de tal direito tem que ser a expressão fiel desta cultura, para ter validade.

Juristas de espírito prático podem estranhar que queiramos subordinar o direito do trabalho a tais determinações doutrinárias. Mas é que cumpre subtrair os seus problemas do mero comentário, para trata-los com maior elevação cultural. Aspiramos para aquele direito, mormente no que se refere à cultura nacional, um sistema científico, organico e vitalizado, por meio do qual se possa precisar conceitos do novo direito, dentro de mutua coerência e unidade. As concepções jurídicas, dêste modo serão mais exatas e precisas, e não terão a dubiedade e vaguidade características de sistemas subjetivistas, sempre falhos e contraditórios.

Quem se dedica ao estudo do direito social e deseja aprofundá-lo nos seus fundamentos históricos, científicos e filosóficos, condição essencial da verdadeira cultura jurídica, precisa meditar seriamente sôbre os pricípios mencionados.

De acôrdo com essa orientação, o estudo do direito ảo trabalho deve começar do conceito do trabalho, para examiná-lo através da sua evolução histórica, apreciando, então, melhor as relações do trabalho na época atual.

A respeito dêsse assunto, Gustavo Radbruch dá-nos magistral lição. "Na ordem jurídica romana, ensina o famoso professor da Universidade de Heidelberg, a relação do trabalho acha-se fudamentada sôbre os direitos reais: o operário era um escravo, uma propriedade do senhor, uma cousa. Só um Direito que estava acostumado a considerar o obreiro como uma cousa, podia aproximar incluso na denominação - o arrendamento de serviço ao arrendamento de coisas. Pelo con- 
trário, a Idade Média fundamentou a relação de trabalho sôbre os direitos pessoais : o dever de trabalho se desprende da categoria pessoal; a vassalagem (Edrigkeit) obriga a prestações pessoais para com o senhor, porém ao mesmo tempo concede frente a êste um direito à proteção e assistência, tirando assim uma mutua relação de fidelidade. Finalmente, a idade moderna apoia a relação de trabalho sôbre o direito crédito, sôbre o contrato livre. Esta liberdade jurídico-formal de contratação significava certamente liberdade para a parte econômica mais forte, para o patrão, o qual pode esperar até que se lhe solicite trabalho; porém de nenhum modo para a outra parte mais débil, para o obreiro, o qual, contratando só com o patrimonio dos seus braços e levando o estomago vazio tem que aceitar o trabalho ali onde o encontra e tal e como o encontra; tem que submeter-se de gráu ou por força das condições que lho oferece a outra parte. Sob a aparência de liberdade e igualdade em ambas as partes, implica, na realidade, sob distinta forma jurídica, o sistema superado de servidão dos operários; com a única diferença, em contra, de que tal sistema, se bem convertia às distintas classes de servos numa espécie de propriedade do senhor territorial, impunha-lhe a êste o dever de proteção e assistência para com os homens a êle confiados; enquanto no sistema de liberdade contratual (existente em aparência) limita as relações entre o patrão e o obreiro ùnicamente aos deveres contratuais mutuos, prescindindo de tôda base ético-social. A relação de servidão medieval foi certamente uma instituição jurídica que violava a dignidade humana; porém uma relação que ao fazer, descaradamente, os homens objeto delas, estava configurada precisamente para êste objeto, isto é, para o homem, e por isto se achava impregnada de moralidade social. 0 sistema de liberdade contratual vê na relação de trabalho ùnicamente a troca de dois bens patrimoniais, que considerava homogeneos; trabalho e salário; desconhece, pois ,que o trabalho não é um hem patrimonial como os demais, que finalmente não é algo distinto do homem inteiro. $\mathrm{E}$ em correspondência com aquela idéia, o sistema de liberdade contratual estrutura a relação de trabalho como se a força dệste fôsse uma coisa e não um homem". 
Tais fatos originaram graves perturbações na sociedade hodierna, traduzidas por greves e revoluções. Surge outra vez a questão social como consequência do desequilíbrio da vida social, do equilíbrio produzido pela exploração do trabalho.

A questão social empolgou de tal modo a nossa época, que procuraram resolve-la grandes forças da sociedade, como a Escola, a Igreja e o Estado, e também ainda eminentes filosofos, pensadores, economistas, moralistas, enfim, homens de pensamento e homens de ação. É que a questão social se transformou no grande problema da atualidade. Todos estão convencidos que da sua solução depende o futuro da humanidade.

Realmente, nos tempos hodiernos, o antagonismo entre a esfera do capital e a esfera do trabalho se acentuou pronunciadamente, preponderando na esfera do capital a riqueza, o luxo, a boa vida, o conforto e o prazer, enquanto na esfera do trabalho, sempre predominou a dôr, o sofrimento e a miséria. De um lado, pois, se colocou o capitalismo, a plutocracia, a séde insaciável de lucro, o egoísmo desenfreado, a exploração do operariado, com a deshumanização da sociedade; de outro lado, o trabalho, como escravo do capital, sempre desprotegido e quasi inteiramente desamparado, não tinha direito algum dai a luta entre o capital e o trabalho, que trouxe o choque violento entre as classes sociais e desordens em todos os sentidos. Assim, a sociedade perdeu o seu equilíbrio. As suas estruturas abalaram-se. Compreendeu-se, então, que é preciso fazer justiça ao trabalhador; a harmonia entre o capital e o trabalho está em o capital reconhecer os direitos legítimos do trabalho, e o trabalho, nestas condições, não hostilizar o capital. "A missão do novo Direito obreiro, afirma Radbruch, estriba em conceder validade aos direitos humanos do operário e estruturar o vinculo de trabalho como uma relação jurídico pessoal, sôbre um novo plano, sôbre o plano da liberdade pessoal. O Direito obreiro é uma organização contra os perigos da liberdade contratual jurídico-formal no campo das relações do trabalho; ora pondo imediatamente limites legais a dita liberdade, graças a preceitos "taxativos" ou "imperativos" (proteção do obreiro); bem ligando o contrato individual do trabalho entre o obreiro e 
o patrão aos contratos coletivos concluidos entre as associações de empresários e de obreiros (contratos de tarifas); bem concedendo ineludiveis efeitos jurídico-públicos, ao fato do contrato de trabalho (como, por exemplo, os direitos e deveres do seguro social e da constituição de emprêsa); bem, finalmente, promovendo o ajuste de contratos coletivos de trabalho, estabelecendo medidas de previsão para o caso de que não se obtenha o seu ajuste e tratando de remediar a insegurança de yosição produzida pela liberdade contratual (Bolsas de trabalho e assistência aos desempregados). De tôdas estas medidas, faremos ressaltar aqui como as mais representativas da especial natureza jurídica do Direito obreiro, o contrato coletivo de trabalho e a constituição da emprêsa".

\section{GENESE DO DIREITO DO TRABALHO}

O trabalho como fenômeno jurídico é a grande realidade da época para todo espírito conciente e esclarecido, para todos aquêles que se sentem fadados a trabalhar pelo bem da coletividade e do próprio gênero humano, êste fato assume a maior importância, e, como tal, exige a atenção das pessoas mais cultas do nosso tempo. Sim, por que o novo direito do trabalho é o sustentáculo da civilização atual e constitui a suprema esperança das almas que ainda não se desesperaram do futuro e crêem sinceramente no advento de uma nova era.

Mas vejamos de como se originou êsse novo direito. Em pleno século XIX, que foi o século da produção da riqueza, quer dizer, nêste período histórico, a máquina a vapôr e a larga utilização do combustível possibilitaram que se produzisse tudo em maior escala com grande rendimento, como nunca se alcançou anteriormente. Eis a Revolução Industrial. Ela provocou profundas transformações sociais, operando mudanças ra esfera econômica, política e cultural. Daí em diante a civilização tomou um rítmo acelerado. Fundaram-se em tôda a parte fábricas e usinas. Houve a concentração operária, nas 
mais importantes metrópoles do mundo. 0 capitalismo atingiu o auge com o liberalismo econômico e a liberdade política e social. Essa expansão industrial, que tantos benefícios trouxe ao homem em matéria de confôrto acentua, porém, o fenômeno da desigualdade entre as classes, e ao lado de uma minoria de ricos estende-se uma maioria de pobres. Aquela estrutura econômica, dentro dos seus princípios fundamentais, torna os ricos cada vez mais ricos e os pobres cada vez mais pobres. Sobrevem, então, a grande crise dos tempos. No cenário social multiplicam-se as greves, lutas de classe, revoluções e até a guerra, que, pela primeira vez na história, toma proporções mundiais.

Nêstes têrmos, a questão social apresenta-se como o problema da época, que sòmente encontra a sua solução na legislação do trabalho. Assim começam a aparecer as leis sôbre o salário mínimo, acidentes do trabalho, sôbre a regulamentação do trabalho das mulheres e dos menores, jornada de trabalho de oito horas, obrigatoriedade do descanso hebdomadário, seguro e previdência social, leis que vêm atenuar a violência do conflito entre o capital e o trabalho. $\mathrm{O}$ Estado, em tais circunstâncias, foi obrigado a intervir em favor dos trabalhadores, e daí o caráter protetor e tutelar do trabalho do novo direito. Como muito bem acentua Gallard Folch: "Esta nova realidade social, a aparição do obreirismo como classe, com consciência da sua existência de uma parte, e, de outra, com necessidades específicas, tinha que ter a sua tradução e correspondência no campo jurídico e modalizar a História do Direito, marcando na mesma um período em que predominasse a legislação do trabalho. Causa coadjuvante dêste fenômeno jurídico o foi também a tendência ao estatismo, tão pronunciada no Direito público contemporâneo. Se não houvesse coincidido esta causa com a anterior, o desenvolvimento da legislação do trabalho não teria sido tão rápido como o foi em todos os países industriais desde o último terço do século XIX até os nossos dias. A marcha ascendente do Estado, apesar das afirmações e dogmas do doutrinarismo liberal, era um fato inquestionável. Êsse doutrinarismo poude impôr posições abstencionistas nos 
primeiros tempos do industrialismo, posições que agravaram, até o indizível, a miséria obreira; porém quando, ao conjuro de uma necessidade social por todos sentida, rompeu-se, de fato, com êstes prejuízos, ainda que todavia em aparência se seguira dando culto a aquêles dogmas, poude-se dispôr de um instrumento formidável de regulamentação e ordenação social, o Estado, que havia ido crescendo ininterruptamente em potência, em meios e possibilidades".

Nestas condições, os problemas fundamentais do novo direito se relacionam com as condições de vida e desenvolvimento da sociedade, porque, não podemos ignorar, que êle acaba de surgir de uma civilização agonizante, e tem de se firmar na época, para se desenvolverem em seguida, promovendo o advento de uma nova era, de que constitui elemento essencial. Assim, êste novo direito como processo civilizador se traduz em poderosa fôrça, ao mesmo tempo, estática e dinâmica, de ordem e de progresso, que obedece como sempre sustentamos na nossa cátedra de professor de direito, aos seguintes princípios: $10^{\circ}$ - a nova cultura jurídica consiste na vitalização dos verdadeiros valores tradicionais, e, na evidenciação dos vabres de caráter jurídico, resultante das condições específicas dos nossos tempos, e como reconhece os direitos novos, de acôrdo com o imperativo categórico da época, deve ser, ao mesmo tempo, altruística, social e humana; $2 .^{\circ}$ - essa cultura se vitalizará pela reabilitação da filosofia do direito. Esta disciplina, integrada no seu objeto verdadeiro, estruturará num todo orgânico o direito vigente, como lhe estabelecer na época atual, os principais problemas e definir-lhe as mais pronunciadas tendências de desenvolvimento no futuro; $3 .^{\circ}$ - a nova cultura jurídica criará, para atingir os seus objetivos práticos, uma técnica muito aperfeiçoada, capaz de facilitar a marcha do curso da atividade jurídica por boa organização judiciária є consequente melhoramento do processo, dando-lhe, de acôrdo com a exigência da época, maior rapidêz e simplicidade, para a justiça ser realmente justificada.

Agora, mais uma vez acentuamos, que a solução dêsses problemas está investida, na época atual, da maior importância. 
Dela dependem os destinos da humanidade. Realmente, é mistér o novo direito para acabar com a confusão reinante, para exterminar o caos na sociedade, restabelecendo a ordem e a segurança social por meios competentes, uma vez que os processos tradicionais se consideram falidos. Nenhum espírito consciente e esclarecido dos nossos tempos pode ignorar êsses fatos. 0 direito é o sustentáculo da civilização.

Mas cumpre aqui acentuar uma verdade. 0 novo direito se diferencia, em certos aspectos, do velho, que estabelecia as suas normas por processos inconscientes, em costumes tradicionais, em fatos repetidos e constantes. Êsse processo é muito deficiente e não se coaduna com a época. Além de vagaroso c rotineiro, pode ser errôneo e viciado, estabelecendo regras de conduta condenáveis, porque só consulta a lei do menor esfôrço, as situações estabilizadas e a estática social. Hoje, o direito tem de ser dinâmico e acompanhar as tendênicias dos nossos tempos. A adaptação jurídica deve ser consciente. $\mathrm{E}$ o que favorece êsse acêrto no procedimento é a ciência com os seus conhecimentos objetivos da atualidade e a previsão dos acontecimentos futuros. A cultura jurídica quer um direito moderno e atualizado, um direito prático e técnico, e não admite mais a vigência de um direito rotineiro, formalístico em excesso e artificial, mormente quando tudo segue o rítmo acelerado da vida dos nossos tempos.

\section{V}

\section{AUTONOMIA DO DIREITO DO TRABALHO}

Pode-se afirmar que o direito do trabalho, nos tempos atuais, adquiriu plena autonomia, isto é, autonomia legislativa, jurisdicional, científica e didática. Autonomia legislativa, porque já se emancipou do direito civil, e não se confunde com c) direito comercial, com o direito político ou com o direito administrativo, possuindo abundante legislação; autonomia jurisdicional, porque dispõe de uma jurisdição especial, constituída por Tribunais de Trabalho; autonomia científica, porque 
tem o seu âmbito próprio, não coincidente com o de nenhuma outra ciência, relacionando a multiplicidade dos fatos trabalhistas dentro de um sistema; autonomia didática, porque hoje, é lecionada nas Faculdades de Direito e em certas entidades universitárias numa cadeira independente.

O direito do trabalho é, pois, um direito autônomo cujo objeto deve ser exatamente definido. Assim pensam tratadistas como Barassi, Pergolese, Asquini, Kaskel, Seggle, Gallart, Botija, Castán, Cabanellas e tantos outros, que se ocuparam minunciosamente do assunto. "A legislação do trabalho, sustenta Gallart, constitui uma especialidade jurídica que chamamos Direito do Trabalho, porque as suas instituições brotaram cbedecendo a causas que lhe são específicas, porque tem fatores próprios de desenvolvimento, porque a sua matéria está perfeitamente delimitada na realidade social, e porque os seus fundamentos doutrinários são diferentes dos das outras esferas do direito". Botija afirma: "Pela expressada uniformidade de fins ou propósitos e pela amplitude de relações que se encerram nos seus confins, é inegável que, no Direito do Trabalho, dão-se dois dos cinco requisitos que, em geral, se exig'em a um ramo do Direito para conferir-lhe a sua autonomia científica: unidade de matéria e um mínimo de extensão no seu campo ou esfera de competência.

Ficavam por demonstrar os outros três requisitos: coincidências de sistema, certa densidade de doutrina... e ainda alguns pormenores externos que tão prezados foram para o positivismo jurídico, a saber, a especialização das normas".

Dentro dêsse ponto de vista, e procedendo com o máximo rigor na determinação do objeto próprio, dos problemas peculiares e do método específico, o direito do trabalho como um direito especial só pode ser a doutrina da relação do trabalho, isto é, das relações entre patrões e empregados nas suas diversas atividades no tempo e no espaço, das relações do trabalhador com o Estado, para os efeitos da proteção e tutela do trabalho. "Produzem-se tais relações, ensina Kaskel - Dersch, de três maneiras, umas com a Emprêsa, em consequência especialmente da prestação de trabalho (o contrato de trabalho); 
outras, com os companheiros da mesma Emprêsa ou da mesma profissão (constituição do trabalho), e, finalmente, outra, com o Estado para proteger o trabalho".

A nossa Consolidação das Leis do Trabalho ficou com a melhor doutrina, quando, na sua Introdução, fixou os seguintes conceitos:

"Art. 1. ${ }^{\circ}$ Esta Consolidação estatui as normas que regulam as relações individuais e coletivas de trabalho, nela previstas.

Art. 2. ${ }^{\circ}$ Considera-se empregador a emprêsa, individual ou coletiva, que, assumindo os riscos da atividade econômica, admite, assalaria e dirige a prestação pessoal de serviços.

$\S 10^{\circ}$ Equiparam-se ao empregador, para os efeitos exclusivos da relação de emprêgo, os profissionais liberais, as instituições de beneficênçia, as associações recreativas ou outras instituições sem fins lucrativos, que admitirem trabalhadores como empregados.

$\S 2 .^{\circ}$ Sempre que uma ou mais emprêsas, tendo embora cada uma delas personalidade jurídica própria, estiverem sob a direção, contrôle ou administração de outra, constituindo grupo industrial, comercial ou de qualquer outra atividade econômica, serão, para os efeitos da relação de emprêgo, solidàriamente responsáveis a emprêsa principal e cada uma das subordinadas.

Art. $3 .^{\circ}$ Considera-se empregado tôda pessoa física que prestar serviços de natureza não eventual a empregador, sob ¿ dependência dêste e mediante salário.

Parágrafo único. Não haverá distinções relativas à espécie de emprêgo e à condição de trabalhador, nem entre o trabalho intelectual, técnico e manual".

O conjunto dessas relações do trabalho pode ser observado metódica e sistemàticamente, nas mais variadas manifestações da sociedade hodierna, caracterizada pela mais intensa industrialização, principalmente nas grandes metrópoles. Assim, no estudo dessa matéria, não procedemos apriorísticamente, através do método dedutivo, mas podemos comprovar os fenô- 
menos, indutivamente, na análise minuciosa da realidade social contemporânea.

Por isso mesmo não nos preocupamos sòmente com afirmar a autonomia do direito do trabalho, condição, entretanto, essencial para uma especialização profunda da matéria. Não. Desejamos mais do que isto, promover as relações desta disciplina com os demais ramos do direito, com as outras ciências sociais e, sobretudo, com a Cultura, para fecundar o seu campo com novas idéias, princípios e doutrinas.

Eis a razão por que aqui nos ocupamos largamente com a Filosofia do Trabalho. 